\title{
Potential influence of water level changes on energy flows in a lake food web
}

\author{
WANG YuYu ${ }^{1,2}$, YU XiuBo $^{1 *}$, LI WenHua $^{1}, \mathrm{XU} \mathrm{Jun}^{3,4}, \mathrm{CHEN}^{\mathrm{YuWei}}{ }^{5}$ \& FAN Na ${ }^{1,2}$ \\ ${ }^{1}$ Key Laboratory of Ecosystem Network Observation and Modeling, Institute of Geographic Sciences and Natural Resources Research, Chinese \\ Academy of Sciences, Beijing 100101, China; \\ ${ }^{2}$ Graduate University of Chinese Academy of Sciences, Beijing 100049, China; \\ ${ }^{3}$ Donghu Experimental Station of Lake Ecosystems, State Key Laboratory of Freshwater Ecology and Biotechnology of China, Institute of Hydro- \\ biology, Chinese Academy of Sciences, Wuhan 430072, China; \\ ${ }^{4}$ Institute of Ecology, Lund University, Ecology Building, SE-223 62 Lund, Sweden; \\ ${ }^{5}$ Nanjing Institute of Geography and Limnology, Chinese Academy of Sciences, Nanjing 210008, China
}

Received May 27, 2011; accepted June 24, 2011

\begin{abstract}
Large seasonal water-level fluctuations may influence isotopic signatures of primary producers and the types and amounts of these potential food sources accessible to aquatic fauna of Poyang Lake, the largest freshwater lake in China. In this study, the isotopic signatures of primary producers and consumers were determined, stable carbon and nitrogen isotope analysis and mixing models were combined to investigate the influence of water levels on the diet and isotopic composition of Poyang Lake fish and invertebrates. Five potential food sources (seston, benthic organic matter, aquatic macrophytes, attached algae, and terrestrial plants), 4 species of invertebrates, and 10 species of fish were collected from the lake area during dry and wet seasons between January 2009 and April 2010. The $\delta^{13} \mathrm{C}$ values of invertebrates and most fish were within the range of $\delta^{13} \mathrm{C}$ values of the potential food sources for both seasons. The $\delta^{13} \mathrm{C}$ values of invertebrates and most fish were lower in the dry season than in the wet season, whereas the $\delta^{15} \mathrm{~N}$ values exhibited different patterns for different species. Mixing models indicated that the most important food sources for common lake fauna were seston in the dry season and aquatic macrophytes and terrestrial plants in the wet season. The fauna were more omnivorous in the wet season than in the dry season. The food web dynamics of Poyang Lake are strongly influenced by changes in the abundance and accessibility of different basal food sources that occur because of seasonal flood pulses. The trophic links within the aquatic communities of Poyang Lake are modified by water-level fluctuations.
\end{abstract}

stable isotopes, seasonal food sources, IsoSource model, water level, Poyang Lake

Citation: Wang Y Y, Yu X B, Li W H, et al. Potential influence of water level changes on energy flows in a lake food web. Chinese Sci Bull, 2011, 56: 2794-2802, doi: 10.1007/s11434-011-4649-y

The mechanism by which energy and materials are transferred from the bottom to the top of food webs is important in ecosystem studies because it has a marked influence on trophic interactions, community structure and ecosystem processes [1,2] and modifies major ecosystem functions, such as nutrient cycling and primary productivity [3]. The extent, frequency and duration of water-level fluctuations are dominant forces controlling the functioning of lake ecosystems since aquatic habitats and feeding or breeding

*Corresponding author (email: yuxb@igsnrr.ac.cn) grounds are gained or lost as water levels fluctuate [4-6]. Shallow lakes are especially sensitive to water-level changes caused by either manmade changes or natural disasters (floods or droughts) that exceed the physiological limits and have deleterious effects on biota [4-7]. Seasonal water-level fluctuations could directly influence many environmental factors including water temperature, dissolved oxygen concentration and nutrient concentration, and biological factors such as primary production, organic carbon contents and fish densities also could be affected [8-10]. As water levels fluctuate, the distribution and structure of habitats from 
riparian toward pelagic open water bodies varies and these changes may influence food webs by facilitating the movement of alternative potential basal resources to consumers [8-10]. The available potential food resources for consumers are scarce and less varied in the dry season, whilst in the wet season water may bring consumers into contact with a greater abundance and diversity of food resources such as terrestrial plants [8-10].

Determining the major basal food sources for lacustrine food webs is a major challenge because of the diversity in primary producers and the complex mobility of consumers. However, this problem has been greatly facilitated by measurement of stable carbon and nitrogen isotope ratios $\left(\delta^{13} \mathrm{C}\right.$ and $\left.\delta^{15} \mathrm{~N}\right)$ to identify carbon sources and understand trophic relationships in aquatic food webs [11-16]. Advances in isotopic mixing models provide opportunities to use both ${ }^{13} \mathrm{C}$ and ${ }^{15} \mathrm{~N}$ to quantify the contributions of different sources to consumers. For example, studies of streams and floodplains [8,9,14], estuaries [13,17-19], and wetlands $[20,21]$ have used stable isotope analyses to estimate the relative importance of autochthonous and allochthonous production for aquatic food webs and their temporal variations. However, fluctuations in lake water levels and their interactions with food web dynamics has received limited attention $[5,6]$.

Poyang Lake, the largest freshwater lake in China, is one of only two lakes still freely connected to the mid-lower portion of the Yangtze River Basin [22]. The annual waterlevel fluctuation averages approximately $12.5 \mathrm{~m}$ [23], and plays an important role in maintaining the unique biota of the Yangtze River floodplain ecosystem [22,24]. However, the lake has been damaged by drastic changes caused by human activities, including population growth, hydrological flow alterations, lake-to-farmland conversions and industrialization [23]. To infer the potential effects of anthropogenic changes in water level occurring in such ecosystems it is necessary to better understand the effects of seasonal water level fluctuations on food webs. The aim of this study was to assess how water-level changes influence the food webs in Poyang Lake. The relative importance of the most significant basal production sources supporting fish and invertebrates were examined using a mixing model.

\section{Materials and methods}

\subsection{Study area}

The lake is a dynamic system located in south China. Five main tributaries (Raohe River, Xinjiang River, Fuhe River, Ganjiang River, and Xiushui River) drain into Poyang Lake $\left(28^{\circ} 22^{\prime}-29^{\circ} 45^{\prime} \mathrm{N}, 115^{\circ} 47^{\prime}-116^{\circ} 45^{\prime} \mathrm{E}\right)$ and the catchment area is $162225 \mathrm{~km}^{2}$ [23] (Figure 1). The lake receives the majority of its water through its tributaries or directly from precipitation and has dramatic seasonal hydrological fluctu-

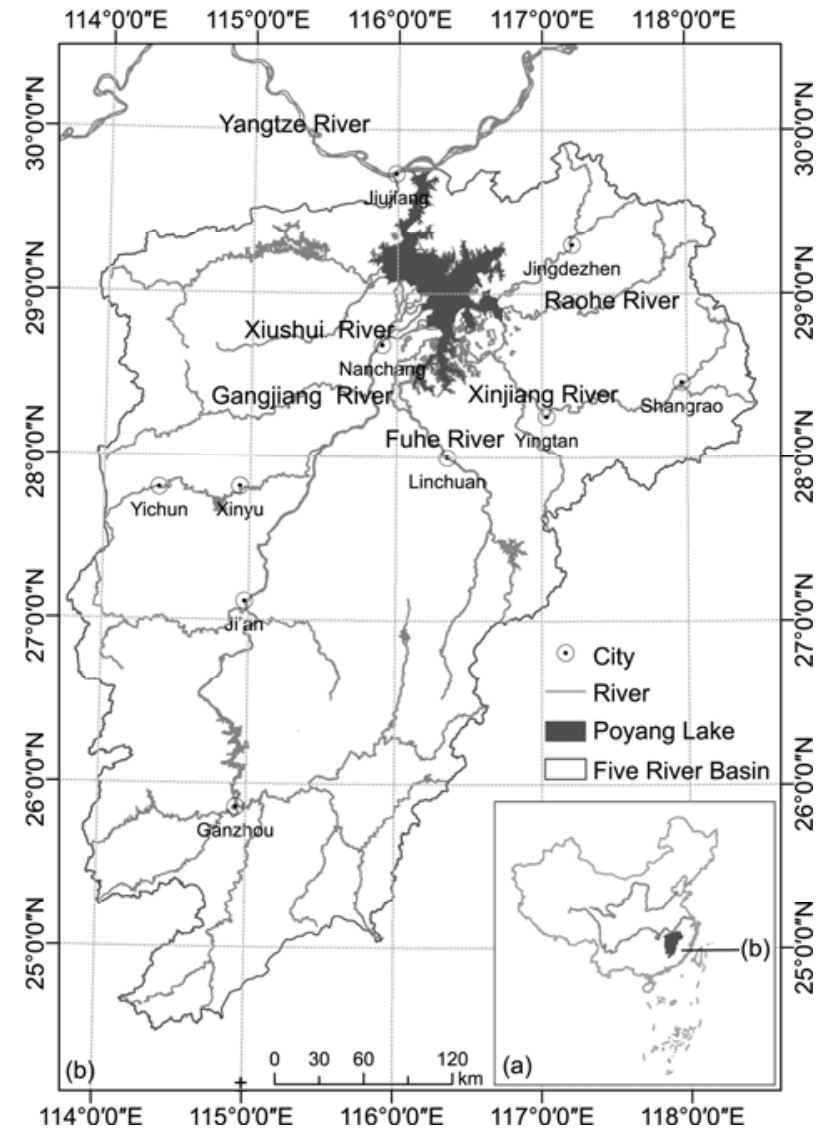

Figure 1 Location of Poyang Lake and the surrounding Five-River Basin in southern China (a) and the 5 main rivers forming the basin with main towns (b). The shaded area denotes the location of the Five-River Basin in China.

ation in the water level during the wet (from April to September) and dry (October to March) seasons [24]. Seasonal switching occurs, from a turbid state in the dry season to a clear state in the wet season during the monsoon in summer [25]. The increase in water level during the wet season also results in a concomitant increase in lake area and decrease in wetland area, plus inundation of riparian habitats [26] (Figure 2(a)). Comparisons of averaged monthly water-level fluctuations in Poyang Lake before and after the Three Gorges Dam was built have shown that the water level during the dry season was obviously lower after the great dam started operating (Figure 2(b)). Extensive grasslands, of mainly emergent sedges and warm season grasses, occur on creek banks and along the fringes of lakes formed by the rivers that drain in Poyang Lake. Macrophytes in the hydrophyte zone are dominated by Carex sp. and Artemisia selengensis, whereas the main submerged aquatic macrophytes are Ceratophyllum demersum, Potamogeton malaianus, Potamogeton crispus, and Hydrilla verticillata [27]. Vegetation in the riparian part of the lake typically greens up in spring and then submerges during summer when inundation increases the water level in the wet season [27]. The plants green up again in autumn, when water levels recede and vegetation emerges [27]. 

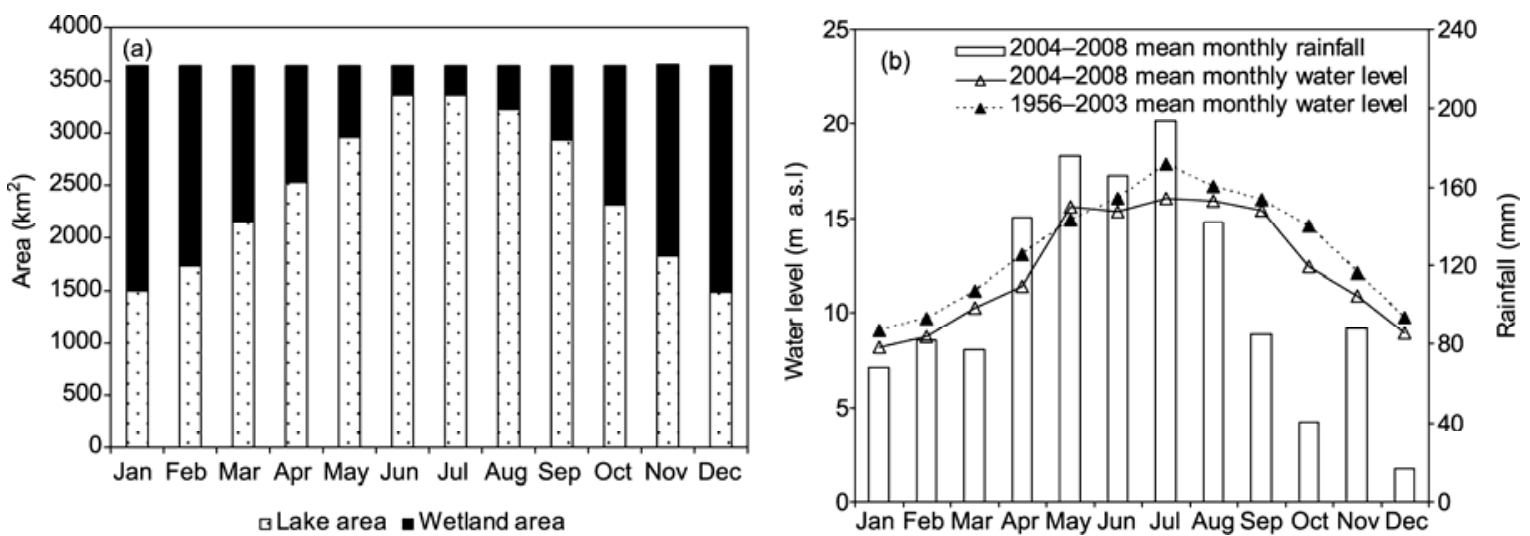

Figure 2 (a) Monthly composition variations of the main lake area and natural wetland area of Poyang Lake. (b) Monthly mean water-level fluctuations in Poyang Lake before and after the Three Gorges Dam was built, and variations in rainfall between 2004 and 2008.

\subsection{Sample collection}

Sampling was conducted at Poyang Lake during the dry and wet seasons. Dry season samples were obtained on 10 January 2009, 10 October 2009, and 10 January 2010; wet season samples were obtained on 10 April 2009, 10 July 2009, and 10 April 2010. Two abundant macrobenthic species: filter-feeding mussel (Corbicula fluminea) and surfacegrazing snail (Bellamya aeruginosa) [28], 2 omnivorous shrimp species (Exopalaemon modestus and Macrobrachium nipponensis), and 10 dominant fish species (herbivore: Parabramis pekinensis; planktivore: Hemiculter leucisculus; omnivores: Cyprinus carpio, Pelteobagrus nitidus, Pelteobagrus vachelli, and Saurogobio dabryi; zooplanktivore: Coilia brachygnathus; carnivores: Silurus asotus and Siniperca chuatsi; detritivore: Parabotia fasciata) [29] were sampled by local fishermen using nets around the central part of the Poyang Lake during both dry and wet seasons. Fresh leaves of terrestrial plants were collected by hand from the wetland area near the dock outside the Poyang Lake Laboratory for Wetland Ecosystem Research, Nanjing Institute of Geography and Limnology, Chinese Academy of Sciences. Two or 3 replicate samples of seston (a mixture of plankton and suspended particulate organic matter), benthic organic matter (BOM), aquatic macrophytes and aquatic invertebrates were collected during sampling from the southern to northern parts of the lake. Seston samples for each site were collected by filtering $1 \mathrm{~L}$ of lake water onto precombusted glass filters $\left(1.2 \mu \mathrm{m}\right.$ pore size, Whatman ${ }^{\circledR}$ GF/C). Invertebrates and BOM samples were collected using a weighted Peterson sampler. Attached algae were slightly scraped off plants and shells of macrobenthos or stones using forceps and scalpels. All samples were rinsed with distilled water and identified in the laboratory.

\subsection{Sample processing and stable isotope analysis}

White muscles were removed from the dorsal of each fish. Shrimps were dissected and their tail muscle tissues were taken. The foot muscles of mussels and snails were removed from the shell. Each sample was oven-dried at $60^{\circ} \mathrm{C}$ to constant weight. Seston and BOM samples were acidified using $1 \mathrm{~mol} / \mathrm{L} \mathrm{HCL}$ to exclude possible carbonate contamination and then dried at $60^{\circ} \mathrm{C}$ for $48 \mathrm{~h}$. Plants were rinsed and identified, then dried at $60^{\circ} \mathrm{C}$ for $24 \mathrm{~h}$. All dried samples were ground to fine powder using a pestle and mortar. Approximately $1 \mathrm{mg}$ of each of the homogenized powder samples was weighed into a separate tin capsule for stable isotope analysis. Analysis of carbon and nitrogen isotopes was carried out using a Finnegan MAT 253 (Thermo Scientific, USA) continuous-flow isotope ratio mass spectrometer coupled with a Flash Elemental Analyzer 1112 (Institute of Geographic Sciences and Natural Resources Research, Chinese Academy of Sciences). Isotope values were expressed as $\delta^{13} \mathrm{C}$ and $\delta^{15} \mathrm{~N}$ (per thousand percent) according to the following equation:

$$
\delta^{13} \mathrm{C} \text { or } \delta^{15} \mathrm{~N}=\left[\left(R_{\text {sample }} / R_{\text {standard }}\right)-1\right] \times 1000,
$$

where $R={ }^{13} \mathrm{C} /{ }^{12} \mathrm{C}$ or ${ }^{15} \mathrm{~N} /{ }^{14} \mathrm{~N}$.

Reference standards were PeeDee belemnite carbonate and atmospheric $\mathrm{N}_{2}$ for $\delta^{13} \mathrm{C}$ and $\delta^{15} \mathrm{~N}$, respectively. Based on replicates of laboratory standards, the analytical precision values were $\pm 0.1 \%$ and $\pm 0.3 \%$ for $\delta^{13} \mathrm{C}$ and $\delta^{15} \mathrm{~N}$, respectively.

\subsection{Data analysis}

The relative importance of the different potential food sources to consumers was determined using an IsoSource model, a multiple source linear mixing model designed for situations in which $n$ isotopes being analyzed and more than $n+1$ sources were likely to contribute [30]. Related producers with similar isotopic compositions were grouped to minimize the number of sources and hence simplify and narrow the range of possible solutions [30]. Five producer groups were considered: (1) seston; (2) BOM; (3) aquatic macrophytes: $C$. demersum Linn., P. malaianus, $P$. crispus, and $H$. 
verticillata leaves; (4) attached algae; and (5) terrestrial plants: leaves of Carex sp. Isotopic values of consumers were corrected for trophic fractionation before the models were run. A mean trophic fractionation value of $3.4 \%$ was assumed for $\delta^{15} \mathrm{~N}$ based on the average fractionation values for crustaceans reported by Post in 2002 [11]. The IsoSource tolerance level used to define an acceptable mass balance was $0.1 \%$. Finally, a dual-isotope $\left(\delta^{13} \mathrm{C}\right.$ and $\left.\delta^{15} \mathrm{~N}\right)$, fivesource mixing model was constructed to calculate feasible ranges of source contributions of each source (0-100\%) at increments of $1 \%$. If mixture isotope values were out of bounds (i.e., outside of the polygon delineated by the sources [31] ), the tolerance value would increase by $0.5 \%$, up to a maximum of $2.5 \%$ [32]. The output values were expressed as the mean percentile value followed by the 1 st and 99th percentile range, as compiled by the mixing model. Likely important food sources were those that had narrower solutions, sources with wide range of distributions and zero values were assumed to be present in the diet, but their importance was minor and thus such data should be treated with caution [31].

Independent-sample Student's $t$-test were used for comparisons of stable isotope data of basal food sources and consumers during dry and wet seasons. All statistic analyses were performed with SPSS 14.0 (SPSS Inc, Chicago, IL, USA).

\section{Results}

\subsection{Seasonal variations in stable isotope composition of food sources and consumers}

In total, 354 consumer and 338 basal-source samples collected during dry and wet seasons were analyzed for their carbon and nitrogen isotope ratios, respectively. In both seasons, terrestrial plants were more ${ }^{13} \mathrm{C}$ depleted (mean value $-30.1 \%$ in the dry season vs. mean value $-29.1 \%$ in the wet season) compared with other potential food sources collected from Poyang Lake, whereas aquatic macrophytes were relatively enriched in ${ }^{13} \mathrm{C}(-21.1 \%$ in the dry season vs. $-21.4 \%$ in the wet season) (Figure 3). Seston had lower $\delta^{13} \mathrm{C}$ values $(-26.9 \%$ in the dry season vs. $-27.2 \%$ in the wet season) compared with BOM $(-25.2 \%$ in the dry season vs. $-24.8 \%$ in the wet season). $\delta^{13} \mathrm{C}$ values were significantly lower in the wet season for attached algae (Student's $t$ test: $t=-11.725, \mathrm{~d} f=5, P<0.001)$, while $\delta^{13} \mathrm{C}$ values for terrestrial plants (Student's $t$ test: $t=80.495, \mathrm{~d} f=10$, $P<0.001)$ and aquatic macrophytes (Student's $t$ test: $t=$ 19.746, $\mathrm{d} f=27, P<0.001$ ), were higher in the wet season (Figure 3). No significant variation in $\delta^{13} \mathrm{C}$ values of seston (Student's $t$ test: $t=-1.144, \mathrm{~d} f=131, P=0.254$ ) and BOM $\delta{ }^{13} \mathrm{C}$ values (Student's $t$ test: $t=1.577, \mathrm{~d} f=48, P=0.121$ ) between dry and wet seasons were observed. During the dry season, attached algae had the lowest $\delta^{15} \mathrm{~N}$ signature (-1.9\%o) and seston had the highest $\delta^{15} \mathrm{~N}$ value (8.6\%o) (Figure 3(a)). In the wet season, among all the food sources, the $\delta^{15} \mathrm{~N}$ value of seston $(5.1 \%$ ) was the lowest and that of aquatic macrophytes was the highest $(8.4 \%$ ) (Figure 3(b)). Only the $\delta^{15} \mathrm{~N}$ value of seston significantly decreased in the wet season (Student's $t$ test: $t=-4.868, \mathrm{~d} f=131, P<0.001$ ); attached algae (Student's $t$ test: $t=18.806, \mathrm{~d} f=5, P<0.001$ ), terrestrial plants (Student's $t$ test: $t=-28.142, \mathrm{~d} f=10, P<$ 0.001 ), aquatic macrophytes (Student's $t$ test: $t=-15.661$, $\mathrm{d} f=27, P<0.001$ ), and BOM (Student's $t$ test: $t=3.345$, $\mathrm{d} f=48, P=0.002$ ) had higher values in the wet season, with
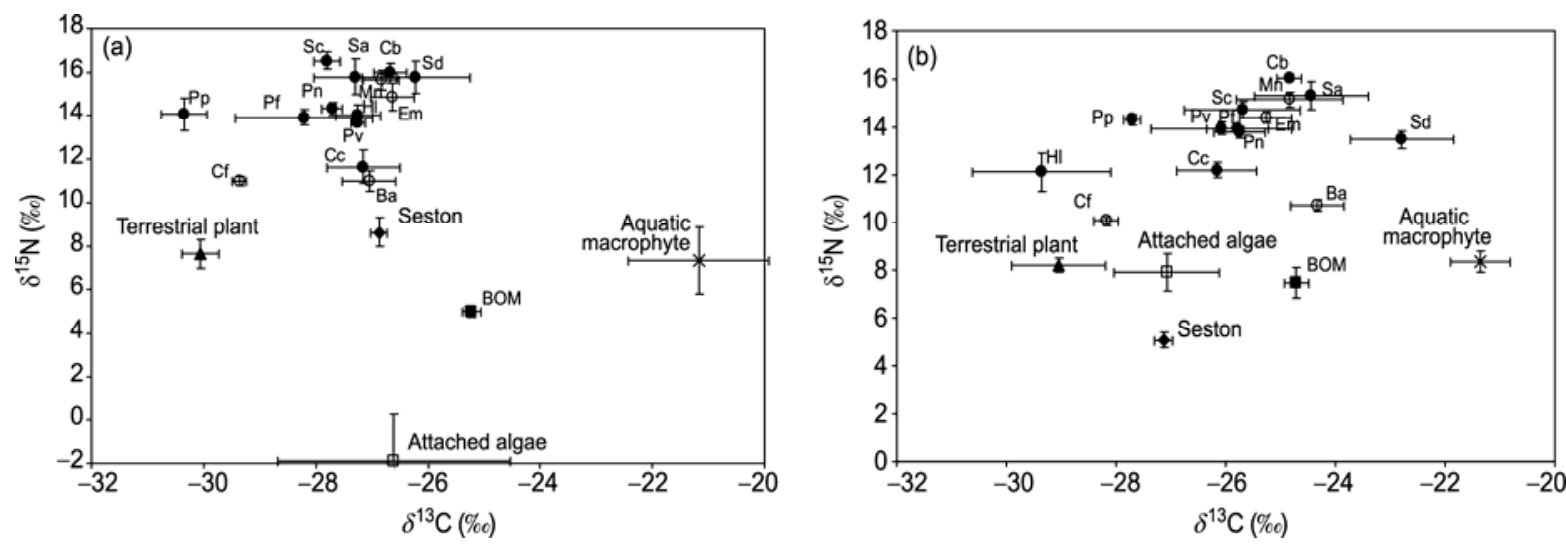

Figure 3 (a) Carbon and nitrogen isotopic compositions (mean $\pm 1 \mathrm{SE}$ ) of producers, invertebrates (white circles), and fish (black circles) collected from Poyang Lake in the dry season. Producers are shown in bold: aquatic macrophytes, $n=3$; attached algae, $n=2$; seston, $n=67$; BOM, $n=23$; and terrestrial plants, $n=4$. Invertebrates: Ba indicates B. aeruginosa $(n=21)$; CF, C. fluminea $(n=59)$; Em, E. modestus $(n=4)$; Mn, M. nipponensis $(n=5)$. Fish: Cb indicates C. brachygnathus ( $n=11)$; Cc, C. carpio $(n=9)$; Hl, H. leucisculus $(n=9)$; Pf, P. fasciata $(n=5) ; \mathrm{Pn}, P$. nitidus $(n=2)$; Pp, $P$. pekinensis $(n=2)$; $\mathrm{Pv}, P$. vachelli $(n=103)$; Sa, S. asotus $(n=5)$; Sc, S. chuatsi $(n=5)$; Sd, S. dabryi $(n=5)$. (b) Carbon and nitrogen isotopic compositions (mean $\pm 1 \mathrm{SE})$ of producers, invertebrates (white circles), and fish (black circles) collected from Poyang Lake in the wet season. Producers are shown in bold: aquatic macrophytes, $n=31$; attached algae, $n=5$; seston, $n=66$; BOM, $n=26$; terrestrial plants, $n=8$. Invertebrates: Ba indicates $B$. aeruginosa ( $n=35$ ); CF indicates $C$. flumin $(\mathrm{n}=42)$; Em indicates E. modestus $(n=14)$; Mn indicates M.nipponensis $(n=6)$. Fish: Cb indicates $C$. brachygnathus $(n=49)$; Cc indicates $C$. carpio $(n=13)$; $\mathrm{Hl}$ indicates H.leucisculus $(n=3)$; Pf indicates $P$. fasciata $(n=4)$; Pn indicates $P$. nitidus $(n=12)$; Pp indicates $P$. pekinensis $(n=3)$; Pv indicates $P$. vachelli $(n=8)$; Sa indicates $S$. asotus $(n=6)$; Sc indicates $S$. chuatsi $(n=7)$; Sd indicates $S$. dabryi $(n=8)$. 
the $\delta^{15} \mathrm{~N}$ value of attached algae increasing the most in the wet season (Figure 3(b)).

$\delta^{13} \mathrm{C}$ values of invertebrates and most fish were within the range of $\delta^{13} \mathrm{C}$ values of the potential food sources for both seasons (Figure 3 ). The $\delta^{13} \mathrm{C}$ values of mussels $(-29.4 \%$ in the dry season vs. $-28.2 \%$ in the wet season) were lower than those of snails $(-27.5 \%$ in the dry season vs. $-24.3 \%$ in the wet season), indicating their dependence on different food sources. Mean $\delta^{13} \mathrm{C}$ values of all the four invertebrates in the dry season were slightly lower than those in the wet season. However, only the variations in snail $\delta^{13} \mathrm{C}$ values (Student's $t$ test: $t=2.424, \mathrm{~d} f=65, P=$ 0.018 ) were significant, variations between seasons for the other three species were not statistically significant (Student's $t$ test: $t=-0.005, \mathrm{~d} f=115, P=0.996$ for mussel, Student's $t$ test: $t=1.786, \mathrm{~d} f=9, P=0.108$ for $M$. nipponensis, Student's $t$ test: $t=1.324, \mathrm{~d} f=15, P=0.205$ for $E$. modestus) (Figure 3). Most feeding guilds of fish collected in the wet season were more ${ }^{13} \mathrm{C}$-enriched than those collected in the dry season, except for H. leucisculus. These changes in the isotope compositions fish may result from a shift to ${ }^{13} \mathrm{C}$ depleted food sources such as aquatic macrophytes. However, these trends were not statistically significant and only the variations in the $\delta^{13} \mathrm{C}$ value of the zooplanktivore $C$. brachygnathus (Student's $t$ test: $t=4.972, \mathrm{~d} f=$ $58, P=0.013$ ) and omnivore $S$. dabryi (Student's $t$ test: $t=$ 2.424, $\mathrm{d} f=11, P=0.034)$ were significant. The herbivores $P$. pekinensis and $H$. leucisculus had the lowest $\delta^{13} \mathrm{C}$ values in dry and wet seasons, respectively. The omnivore $S$. $d a b$ ryi had the highest $\delta^{13} \mathrm{C}$ value in both seasons. In contrast to their carbon isotope signatures, temporal variation of consumers nitrogen isotope signatures did not display consistent patterns. $\delta^{15} \mathrm{~N}$ values of two species of shrimps were much higher than macrobenthos during both seasons. Among fish, carnivorous species were more enriched in ${ }^{15} \mathrm{~N}$ compared with detritivorous and omnivorous fish.

\subsection{Linking different seasonal food sources with consumers: Mixing model results}

In the dry season, among the 5 potential food sources analyzed, seston was identified as the major food source for the snail and the two species of shrimps. Terrestrial plants were identified as the only food source assimilated by mussel and also contributed to the snails diet (Table 1). IsoSource model solutions indicated that seston was the most important source supporting the biomass of all 10 species of fish examined, terrestrial plants also contributed to the diets of $C$. carpio and $P$. pekinensis (Table 1). However, in the wet season, all the consumers shifted to depend mostly on aquatic macrophytes, while terrestrial plants accounted for a further large fraction of food sources for 7 out of the 10 fish species (Table 1). Terrestrial food sources support fish production to a significant extent and the contributions that sustained the consumer productions were greater during the wet season. Mussels assimilated large amounts of both aquatic macrophytes and seston in the wet season whilst snails and the two species of shrimp depended mostly on aquatic macrophytes.

\section{Discussion}

To interpret the results of stable carbon and nitrogen isotope analyses meaningfully it is essential that the primary food sources of interest have distinct isotopic signatures [12,17, $20,31]$. In the present study, relatively $\delta^{13} \mathrm{C}$-depleted values for terrestrial plants and $\delta^{13} \mathrm{C}$-enriched values for aquatic macrophytes were distinct from other basal sources. $\delta^{13} \mathrm{C}$ values of terrestrial plants, aquatic macrophytes and attached algae also showed significant seasonal variations (Figure 3). Dissolved inorganic carbon (DIC) concentration in the lake water and phytoplankton species composition and physiology may affect the $\delta^{13} \mathrm{C}$ of seston, aquatic macrophytes and terrestrial plants [15,18,33-36]. In the wet season, total $\mathrm{N}$ concentration, total $\mathrm{P}$ concentration and the $\mathrm{pH}$ of lake water decreased, whereas temperature and Secchi depth increased [37]. In such an environment, phytoplankton in the wet season would fix more community respired $\mathrm{CO}_{2}$, lead to the decline in the $\delta^{13} \mathrm{C}$ value of seston [36]. $\mathrm{Xu}$ et al. [34] reported significant positive correlations of seston $\delta^{13} \mathrm{C}$ values with total $\mathrm{P}$ and total $\mathrm{N}$ in the water column. In addition, modification in the terrestrial carbon contribution could also lead to changes in the isotope composition of seston and BOM [10,14,38,39]. Bacterial decomposition of detritus may yield a lower ${ }^{13} \mathrm{C}$ value compared with the original plant material, which would influence the $\delta^{13} \mathrm{C}$ value of $\mathrm{BOM}[18,35]$. The ${ }^{13} \mathrm{C}$ ratio of attached algae is influenced by the diffusion of $\mathrm{CO}_{2}$ through the boundary layer caused by water turbulence and high water exchange would bring a greater supply of $\mathrm{CO}_{2}[11,38]$.

Although in the present study the five basal sources showed significant seasonal variation in $\delta^{15} \mathrm{~N}$ values, overlaps in the wet season were evident (Figure 3). Initial seston ${ }^{15} \mathrm{~N}$ composition is established by the composition of phytoplankton and their variations in assimilation ability of isotopically distinct dissolved inorganic nitrogen (DIN) [33,39]. For example, $\mathrm{NH}_{4}{ }^{+}$is considerably ${ }^{15} \mathrm{~N}$-enriched (20\%o-30\%o) compared with $\mathrm{NO}_{3}^{-}(<10 \%$ ) $[33,40]$. The proportion of cyanobacteria in the phytoplankton biomass increased in the wet season at Poyang Lake and further contributed to the decrease in the seston $\delta^{15} \mathrm{~N}$ value, because cyanobacteria can directly use atmospheric $\mathrm{N}_{2}$ and have low stable nitrogen isotope fractionation [34,39]. In the wet season, floods brought water contaminated by agricultural drainage and urban sewage, and thus with a high $\mathrm{N}$ load, from the five main tributaries to the main lake [41]. This caused an increase in the $\delta^{15} \mathrm{~N}$ value of aquatic macrophytes 


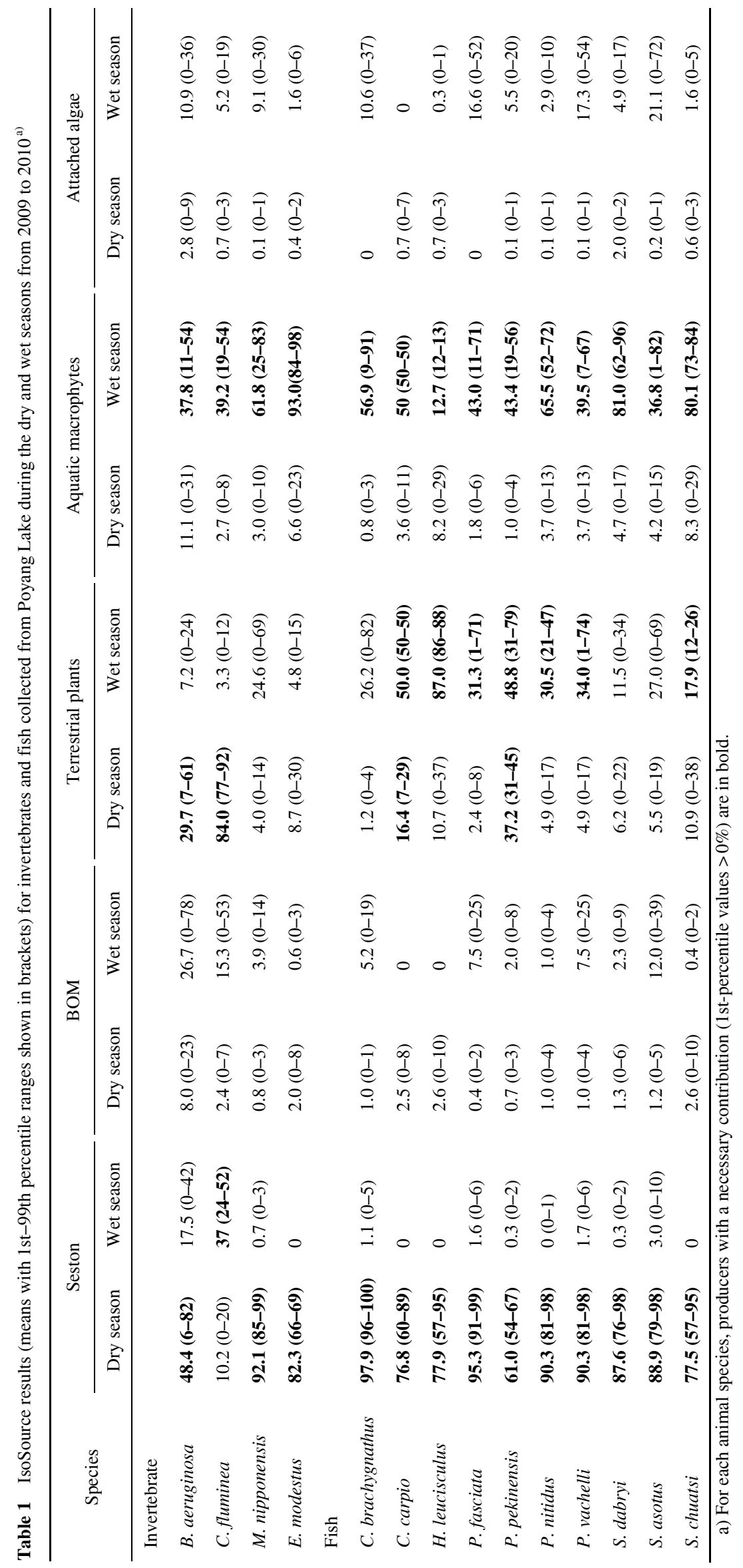


and attached algae [42,43]. Abundant detritus from macrophytes was responsible for the higher $\delta^{15} \mathrm{~N}$ value of BOM in the wet season [44]. The change between anoxic and oxic conditions during the water-land transition and the availability of large amounts of organic material favor denitrification, which would also lead to higher $\delta^{15} \mathrm{~N}$ values for BOM [40]. Rooted species could obtain nitrogen, phosphorus, calcium and other key nutrients from the sediment [42]. The increase in the $\delta^{15} \mathrm{~N}$ value of the terrestrial plant Carex sp. when heavy rainfall and floods occurred indicated a change in the proportion of DIN of the soil $\mathrm{N}$ pool used by these plants associated with periodicity of soil wetting $[18,45]$. This mechanism may explain the increase in the $\delta^{15} \mathrm{~N}$ of terrestrial plants during wet season.

Consumer $\delta^{13} \mathrm{C}$ values are often reported to be representative of the diversity of food sources supporting the food web $[11,12]$. Primary producers and invertebrates have shorter time-integrated isotopic signatures than vertebrates, yet fish also exhibited seasonal isotopic differences [11,12, 17,46]. Among the 10 species of fish collected from Poyang Lake in both seasons, 9 species showed an increase in $\delta^{13} \mathrm{C}$ values in the wet season. It is well known that fish can change their food habits as a consequence of prey availability, which varies with season $[8,10,46]$. Studies of primary producers in Poyang Lake have reported that vegetation biomass has seasonal variations associated with water-level fluctuations: the abundance and species diversity of phytoplankton was higher in the dry season than in the wet season and highest in October in the dry season [47]; biomass of aquatic macrophytes was highest in September in the dry season whilst during winter the aboveground part died and decomposed [27]; biomass of terrestrial plants was highest in April in the wet season and then gradually decreased followed by a second peak in biomass in November in the dry season [27]. In the dry season, when the water level was low, water became turbid and nutrient rich, submerged aquatic macrophyte belts became restricted, algae grew rapidly compared with aquatic macrophytes and the water column had more suspended organic matter. Consumers were concentrated in the central part of the lake and thus the available food was less varied and they mainly relied on seston $[8,48]$. In the wet season, high water levels caused grassy vegetation to decay and submerged aquatic macrophytes to develop. This increase in water level brought additional food sources from terrestrial plants, such as fresh leaves of terrestrial plants, detritus brought by floods, insects falling from flooded vegetation. Moreover, a variety of aquatic invertebrates developing in the land-lake transfer zone become accessible for fish during this period $[8,48]$. Terrestrial inputs to the lake food web may be either through microbial decomposition or involve a detrital food chain bringing carbon from microbes relying on vascular plants to invertebrates through intermediary consumers $[6,8$, $10,13,49,50]$. The feeding behavior shifts of lower trophic level consumers could also influence the stable isotope composition of top-predators $[10,13,15,18]$. However, in this study it was not possible to detect whether the terrestrial food sources came from fish feeding on invertebrates that grazing terrestrial inputs or from feeding on detritus after being metabolized by the microbial loop. These isotopic shifts in consumers were also suggested by the IsoSource model estimation results, which indicated that in the wet season consumers shift to consuming ${ }^{13} \mathrm{C}$-enriched endpoints like aquatic macrophytes and terrestrial plants, not seston. These results were consistent with the findings of several authors from different geographical regions which also reported that fish assemblages collected during low and high water level periods showed shifts in their stable carbon isotope compositions in response to a change in the isotope composition of their food [8-10,49-51].

Changes in consumers $\delta^{15} \mathrm{~N}$ values may result from a shift to different ${ }^{15} \mathrm{~N}$ basal food sources $[10,16,17,50,51]$. IsoSource model results also indicated variations in the temporal shifts of potential food sources assimilated by different species of consumers. Wantzen et al. [8] reported that fish collected in the dry season from the Amazon River had a general increase in $\delta^{15} \mathrm{~N}$ values from wet season to dry season, which indicated more omnivorous feeding during the wet season and elevated carnivory during the dry season because the lake was confined to its basin. In addition, during the wet season, fish become more dispersed in the dense macrophytes in the vast flooded area, thereby reducing interand intra-specific competition and predation risk $[10,48]$. These factors contributed to different seasonal variations of $\delta^{15} \mathrm{~N}$ values among feeding guilds in Poyang Lake at different seasons.

The water-level fluctuation regime combined with the seasonal stages of main primary production (i.e. production of a certain type of food item at a given time) and those of the ontogenetic development of animals (i.e. influence of migration or sexual maturity on feeding behavior) is decisive in the passage of energy sources through the food web $[6,14,19,46]$. The relative availability of autochthonous and/ or allochthonous resources in food webs shifts with gradients of water depth, nutrient concentrations, degree of canopy cover and distance from terrestrial habitats [9,14,17,21]. Freshwater macrobenthos and fish assemblages were based on the productivity of basal food sources $[8,10,18]$. Therefore, trophic links within the fish communities may then be modified by water level changes in Poyang Lake. The hydrologic variations caused by large anthropogenic influences are markedly different from the original natural ones and often change the nutrient supply, littoral habitats and aquatic-terrestrial interface processes [4-6]. Advancement of the rise of the water level in May in the wet season and earlier drop of water levels at Poyang Lake in the dry season have been noted since the Three Gorges Dam began operating (Figure 2(b)). Although Wu et al. [25] predicted that operation of the Three Gorges Dam was more likely to increase the light availability and productivity of $V$. spiralis 
in Poyang Lake in the short term, different species of aquatic plants vary in their ability to survive high-flow conditions such that few or no macrophytes can establish and grow in habitats where high-flow dominates the growing season [42,52]. Terrestrial plant species are also very sensitive to water-level changes as they are only able to establish during dry phases [53]. These changes in vegetation are continually transferred through the food web [54]. Lower water levels in the dry season may invoke the conversion of a water environment to an environment in which sediments are exposed to the air and damage the vegetation sufficiently to push the lake to a turbid state, which would directly affect survival of attached algae and distribution of invertebrate taxa $[6,42,46]$. Changes in the water level can have potentially important environmental effects directly for eulittoral benthic fish communities, which include loss of suitable spawning habitat and shelter availability around the lake edge because of low lake levels [54,55].

\section{Conclusions}

The main findings of this research center on influences of water-level fluctuations on basal food sources and available habitats for aquatic consumers in Poyang Lake. Water-level regulations in the mid-lower Yangtze lakes have resulted in a marked drop in diversity of macrobenthos and fish [22,56]. Economic development is an important issue in Jiangxi Province as it is one of the least developed provinces in China. As a result, the Provincial Government proposed the development of the $51200 \mathrm{~km}^{2}$ Poyang Lake Eco-economic Development Zone around the lake, with the dam as one of the project elements. Li [57] reported on the proposed construction of a dam at the narrowest northern outlet of Poyang Lake and the wide disapproval of this project by Chinese scientists. The Central Government approved the Ecoeconomic Zone in December 2009, but did not approve the dam. Instead, they asked that further scientific assessment be carried out on the likely impacts of the dam. Dudgeon [58] predicted that China's strategy for limiting emissions of greenhouse gases would increase demands for hydropower in the foreseeable future and that much of the Yangtze River will therefore soon be a mere semblance of its natural state, risking loss of what remains of the river's unique biodiversity. $\mathrm{Xu}$ et al. [59] reported an annual mean temperature increase of $0.7^{\circ} \mathrm{C}$ between 2001 and 2005 in the Yangtze River Basin. They predicted that the frequency of natural disasters, such as floods and droughts, would increase, with lower dry season water levels and increasing temperature reducing the extent of floodplain wetlands and habitats for water birds and aquatic biota. O'Reilly et al. [7] demonstrated that regional warming since the beginning of the 20th century had diminished productivity in Lake Tanganyika. Temperature changes already appear to be affecting fish migrations within the Yangtze River and bird migration pathways [59]. As the largest freshwater lake in the Yangtze River Basin, Poyang Lake has an important role. The extent of future water-level fluctuations is currently not assessable and might be more severe than assumed. Considering these factors, before further manipulation of flow regime seasonality and hydrological connectivity in Poyang Lake takes place, more long-term monitoring of plants, macrobenthos, fish assemblages, and even wintering birds is required in this area to ascertain their capacity to tolerate and survive such disturbances.

We would like to thank Dr. ZHANG Lu, Dr. WANG XiaoLong and the staff of Poyang Lake Laboratory for Wetland Ecosystem Research, Nanjing Institute of Geography and Limnology, Chinese Academy of Sciences, for their help in field work and data collection. This work was supported by the National Basic Research Program of China (2009CB421106) and the National Natural Science Foundation of China (30870428), the K. C. Wong Education Foundation and the Knowledge Innovation Program of the Chinese Academy of Sciences.

1 Post D M. The long and short of food-chain length. Trends Ecol Evol, 2002, 7: 269-277

2 Jansson M, Persson L, De Roos A M, et al. Terrestrial carbon and intraspecific size-variation shape lake ecosystems. Trends Ecol Evol, 2007, 22: 316-322

3 Pace M L, Carpenter S R, Cole J J, et al. Does terrestrial organic carbon subsidize the planktonic food web in a clear-water lake? Limnol Oceanogr, 2007, 52: 2177-2189

4 Dudgeon D. Large-scale hydrological changes in tropical Asia: Pospects for riverine biodiversity. Bioscience, 2000, 50: 793-806

5 Coops H, Beklioglu M, Crisman T L. The role of water-level fluctuations in shallow lake ecosystems - Workshop conclusions. Hydrobiologia, 2003, 506-509: 23-27

6 Leira M, Cantonati M. Effects of water-level fluctuations on lakes: An annotated bibliography. Hydrobiologia, 2008, 613: 171-184

7 O'Reilly C M, Alin S R, Plisnier P, et al. Climate change decreases aquatic ecosystem productivity of Lake Tanganyika, Africa. Nature, 2003, 424: 766-768

8 Wantzen K M, de Arruda Machado F, Voss M, et al. Seasonal isotopic shifts in fish of the Pantanal wetland, Brazil. Aquat Sci, 2002, 64: 239-251

9 Roach K A, Winemiller K O, Layman C A, et al. Consistent trophic patterns among fishes in lagoon and channel habitats of a tropical floodplain river: Evidence from stable isotopes. Acta Oecol, 2009, 35: 513-522

10 Perga M, Arfi R, Gerdeaux D. Seasonal variations in fish $\delta^{13} \mathrm{C}$ and $\delta^{15} \mathrm{~N}$ in two West African reservoirs, Sélingué and Manantali (Mali): Modifications of trophic links in relation to water level. Isot Environ Healt S, 2005, 41: 109-123

11 Post D M. Using stable isotopes to estimate trophic position: Models, methods, and assumptions. Ecology, 2002, 83: 703-718

12 Layman C A, Arrington D A, Montana C G, et al. Can stable isotope ratios provide for community-wide measures of trophic structure? Ecology, 2007, 88: 42-48

13 Benstead J P, March J G, Fry B, et al. Testing IsoSource: Stable isotope analysis of a tropical fishery with diverse organic matter sources. Ecology, 2006, 87: 326-333

14 Zeug S C, Winemiller K O. Evidence supporting the importance of terrestrial carbon in a large-river food web. Ecology, 2008, 89: 1733-1743

15 Milligan H E, Pretzlaw T D, Humphries M M. Stable isotope differentiation of freshwater and terrestrial vascular plants in two subarctic regions. Ecoscience, 2010, 17: 265-275

16 Wang Y Y, Yu X B, Xu J. Decreased trophic position as a function of 
increasing body size of a benthic omnivorous fish from the largest freshwater lake in China. Environ Biol Fish, 2011, doi: 10.1007/ s10641-011-9808-0

17 Reid D J, Quinn G P, Lake P S, et al. Terrestrial detritus supports the food webs in lowland intermittent streams of south-eastern Australia: A stable isotope study. Freshw Biol, 2008, 53: 2036-2050

18 Cloern J E, Canuel E A, Harris D. Stable carbon and nitrogen isotope composition of aquatic and terrestrial plants of the San Francisco Bay estuarine system. Limnol Oceanogr, 2002, 47: 713-729

19 Abrantes K, Sheaves M. Incorporation of terrestrial wetland material into aquatic food webs in a tropical estuarine wetland. Estuar Coast Shelf Sci, 2008, 80: 401-412

20 Opsahl S, Golladay S, Smith L, et al. Resource-consumer relationships and baseline stable isotopic signatures of food webs in isolated wetlands. Wetlands, 2010, 30: 1213-1224

21 Taylor A N, Batzer D P. Spatial and temporal variation in invertebrate consumer diets in forested and herbaceous wetlands. Hydrobiologia, 2010, 651: 145-159

22 Fu C Z, Wu J H, Chen J K, et al. Freshwater fish biodiversity in the Yangtze River basin of China: Patterns, threats and conservation. Biodivers Conserv, 2003, 12: 1649-1685

23 Wang X H, Fan Z W, Cui L J, et al. Evaluation on Poyang Lake Wetland Ecosystem (in Chinese). Beijing: Science Press, 2004. 44-50

24 Zhu H H, Zhang B. The Poyang Lake (in Chinese). Hefei: Press of University of Science and Technology of China, 1997. 1-12

25 Wu G F, de Leeuw J, Skidmore A K, et al. Will the Three Gorges Dam affect the underwater light climate of Vallisneria spiralis L. and food habitat of Siberian crane in Poyang Lake? Hydrobiologia, 2009, 623: 213-222

26 Liu Y, Fan N, Yu X B, et al. Identification of wetland boundaries of Poyang Lake and analysis of seasonal change based on remote sensing and GIS technology (in Chinese). Resour Sci, 2010, 32: 22392245

27 Guan S, Lang Q, Zhang B. Biomass of macrophytes of the Poyang Lake with suggestions of its rational explantation (in Chinese). Acta Hydrob Sin, 1987, 11: 219-227

28 Wang H Z, Xu Q Q, Cui Y D. Macrozoobenthic community of Poyang Lake, the largest freshwater lake of China, in the Yangtze floodplain. Limnology, 2007, 8: 65-71

29 Zhang T L, Li Z J. Fish resources and fishery utilization of Poyang Lake (in Chinese). J Lake Sci, 2007, 19: 434-444

30 Phillips D L, Gregg J W. Source partitioning using stable isotopes: Coping with too many sources. Oecologia, 2003, 136: 261-269

31 Phillips D L, Newsome S D, Gregg J W. Combining sources in stable isotope mixing models: Alternative methods. Oecologia, 2005, 144: $520-527$

32 Karube Z, Sakai Y, Takeyama T, et al. Carbon and nitrogen stable isotope ratios of macroinvertebrates in the littoral zone of Lake Biwa as indicators of anthropogenic activities in the watershed. Ecol Res, 2010, 25: 847-855

33 Gu B H, Chapman A D, Schelske C L. Factors controlling seasonal variations in stable isotope composition of particulate organic matter in a soft water eutrophic lake. Limnol Oceanogr, 2006, 51: 2837-2848

34 Xu J, Zhang M, Xie P. Stable carbon isotope variations in surface bloom scum subsurface seston among shallow eutrophic lakes. Harmful Algae, 2007, 6: 679-685

35 France R L. Stable isotopic survey of the role of macrophytes in the carbon flow of aquatic foodwebs. Plant Ecol, 1996, 124: 67-72

36 Gu B, Schelske C L, Waters M N. Patterns and controls of seasonal variability of carbon stable isotopes of particulate organic matter in lakes. Oecologia, 2011, 165: 1083-1094

37 Wang M L. Spatio-temporal distribution of nitrogen and phosphorus and its geochemical modeling in Poyang Lake Catchment (in Chinese). Doctor Dissertation. Nanchang: Nanchang University, 2007

38 France R L. Carbon-13 enrichment in benthic compared to planktonic algae: Foodweb implications. Mar Ecol-Prog Ser, 1995, 124: 307-312

39 Gu B. Variations and controls of nitrogen stable isotopes in particulate organic matter of lakes. Oecologia, 2009, 160: 421-431

40 Syväranta J, Tiirola M, Jones R I. Seasonality in lake pelagic $\delta^{15} \mathrm{~N}$ values: Patterns, possible explanations, and implications for food web baselines. Fund Appl Limnol, 2008, 172/3: 255-262

41 Wang M L, Zhou W B, Hu C H. Status of nitrogen and phosphorus in waters of Poyang Lake Basin (in Chinese). J Lake Sci, 2008, 20: 334-338

42 Lacoul P, Freedman B. Environmental influences on aquatic plants in freshwater ecosystems. Environ Rev, 2006, 14: 89-136

43 Bannon R O, Roman C T. Using stable isotopes to monitor anthropogenic nitrogen inputs to estuaries. Ecol Appl, 2008, 18: 22-30

$44 \mathrm{Xu} \mathrm{J}$, Xie P. Studies on the food web structure of Lake Donghu using stable carbon and nitrogen isotope ratios. J Freshw Ecol, 2004, 19: $645-650$

45 Welker J, Jónsdóttir I, Fahnestock J. Leaf isotopic $\left(\delta^{13} \mathrm{C}\right.$ and $\left.\delta^{15} \mathrm{~N}\right)$ and nitrogen contents of Carex plants along the Eurasian Coastal Arctic: Results from the Northeast Passage expedition. Polar Biol, 2003, 27: 29-37

46 Abrantes K, Sheaves M. Importance of freshwater flow in terrestrialaquatic energetic connectivity in intermittently connected estuaries of tropical Australia. Mar Biol, 2010, 157: 2071-2086

47 Xie M Q, Li C C, Peng C L. Primary studies on community ecology of floating algae in Poyang Lake (in Chinese). Jiangxi Sci, 2000, 18: $162-166$

48 Junk W J, Wantzen K M. The flood pulse concept: New aspects, approaches, and applications-An Update. In: Welcomme R L, Petr T, eds. Proceedings of the Second International Symposium on the Management of Large Rivers for Fisheries. Volume 2. Bangkok: RAP Publication, 2004. 117-149

49 Marshall B G, Forsberg B R, Thome-Souza M J F. Autotrophic energy sources for Paracheirodon axelrodi (Osteichthyes, Characidae) in the middle Negro River, Central Amazon, Brazil. Hydrobiologia, 2008, 596: 95-103

50 Vizzini S, Mazzola A. Seasonal variations in the stable carbon and nitrogen isotope ratios $\left({ }^{13} \mathrm{C} /{ }^{12} \mathrm{C}\right.$ and $\left.{ }^{15} \mathrm{~N} /{ }^{14} \mathrm{~N}\right)$ of primary producers and consumers in a western Mediterranean coastal lagoon. Marine Biol, 2003, 142: 1009-1018

51 Jepsen D B, Winemiller K O. Basin geochemistry and isotopic ratios of fishes and basal production sources in four neotropical rivers. Ecol Freshw Fish, 2007, 16: 267-281

52 Riis T, Biggs B J F. Hydrologic and hydraulic control of macrophyte establishment and performance in streams. Limnol Oceanogr, 2003, 48: $1488-1497$

53 Casanova M T, Brock M A. How do depth, duration and frequency of flooding influence the establishment of wetland plant communities? Plant Ecol, 2000, 147: 237-250

54 Sutela T, Vehanen T. Effects of water-level regulation on the nearshore fish community in boreal lakes. Hydrobiologia, 2008, 613: $13-20$

55 Fischer P, Ohl U. Effects of water-level fluctuations on the littoral benthic fish community in lakes: A mesocosm experiment. Behav Ecol, 2005, 16: 741-746

56 Shu F Y, Wang H J, Pan B Z, et al. Assessment of species status of mollusca in the mid-lower Yangteze Lakes (in Chinese). Acta Hydrob Sin, 2009, 33: 1051-1057

57 Li J. Scientists line up against dam that would alter protected wetlands. Science, 2009, 326: 508-509

58 Dudgeon D. Requiem for a river: Extinctions, climate change and the last of the Yangtze. Aquat Conserv, 2010, 20: 127-131

59 Xu M, Ma C D. Yangtze River Basin Climate Change Vulnerability and Adaptation Report (in Chinese). Beijing: China Water Power Press, 2009. 35-47

Open Access This article is distributed under the terms of the Creative Commons Attribution License which permits any use, distribution, and reproduction in any medium, provided the original author(s) and source are credited. 